\title{
Bingimeering Jourtilal
}

Article

\section{Sensitivity Analysis by the $2^{\mathrm{k}}$ Factorial Experimental Design of $\mathrm{CO}_{2}$ Capture with Amine Gas Treating Process Using Aspen Plus}

\author{
Thapanat Chuenphan ${ }^{1,2}$, Tarabordin Yurata ${ }^{3}$, Teerawat Sema ${ }^{3,4,5}$, \\ and Benjapon Chalermsinsuwan ${ }^{3,4,5,6, *}$ \\ 1 Covestro (Thailand) Co., Ltd., 4-4/1 I-8 Road, Map Ta Phut Industrial Estate, Muang, Rayong 21150, \\ Thailand \\ 2 Program of Petrochemistry and Polymer Science, Faculty of Science, Chulalongkorn University, \\ 254 Phayathai Road, Pathumwan, Bangkok 10330, Thailand \\ 3 Department of Chemical Technology, Faculty of Science, Chulalongkorn University, 254 Phayathai Road, \\ Pathumwan, Bangkok 10330, Thailand \\ 4 Fuels Research Center, Department of Chemical Technology, Faculty of Science, Chulalongkorn \\ University, 254 Phayathai Road, Pathumwan, Bangkok 10330, Thailand \\ 5 Center of Excellence on Petrochemical and Materials Technology, Chulalongkorn University, 254 \\ Phayathai Road, Pathumwan, Bangkok 10330, Thailand \\ 6 Advanced Computational Fluid Dynamics Research Unit, Chulalongkorn University, 254 Phayathai Road, \\ Pathumwan, Bangkok 10330, Thailand \\ E-mail: *benjapon.c@chula.ac.th (Corresponding author)
}

\begin{abstract}
It is well-known that $\mathrm{CO}_{2}$ capture with amine treating process has been used and developed in industry to purify the off-gas from the process- Nowadays, the simulation via computer software is one of the most effective tools to improve and optimize the existing process because there is no environmental effect and uses lower cost compared to the experiments. Generally, for sensitivity analysis, the parameters are studied individually without considering the interaction effects between parameters. In this study, the equilibrium model of $\mathrm{CO}_{2}$ capture by monoethanolamine (MEA) pilot plant was modelled using Aspen Plus by ENRTL-RK thermodynamics property model. A sensitivity analysis with the $2^{\mathrm{k}}$ factorial experimental design was performed. The main and interaction effects of five parameters (which are liquid-gas mass ratio $(\mathrm{L} / \mathrm{G})$, sour gas temperature, lean MEA temperature, lean MEA concentration and $\mathrm{CO}_{2}$ concentration in sour gas) were then investigated. From the sensitivity analysis with the $2^{\mathrm{k}}$ factorial experimental design, liquid-gas mass ratio contributed $75.82 \%$ to $\mathrm{CO}_{2}$ removal efficiency; while $\mathrm{CO}_{2}$ concentration in sour gas and liquid-gas mass ratio $(\mathrm{L} / \mathrm{G})$ occupied $29.14 \%$ and $17.36 \%$ to $\mathrm{CO}_{2}$ removal efficiency and specific heat duty at the reboiler, respectively.
\end{abstract}

Keywords: $\mathrm{CO}_{2}$ capture, simulation, aspen plus, sensitivity analysis, $2^{\mathrm{k}}$ factorial experiment design.

ENGINEERING JOURNAL Volume 25 Issue 4

Received 4 December 2020

Accepted 29 December 2020

Published 30 April 2021

Online at https:/ / engj.org/

DOI:10.4186/ej.2021.25.4.95 


\section{Introduction}

Nowadays, carbon dioxide $\left(\mathrm{CO}_{2}\right)$ is one of the main exhausted gas components, that causes global warming, from many industries, especially petrochemicals, refinery and power plant. Therefore, Carbon Capture and Storage (CCS) has been implemented to remove $\mathrm{CO}_{2}$ along the process in order to reduce its environmental impacts. Chemical absorption with aqueous solution of monoethanolamine (MEA) is considered as one of the well-known technologies for capturing $\mathrm{CO}_{2}$ due to its high reactive rate and simple operating condition, e.g. low temperature and pressure [1]. However, due to incremental increases in production rates to fulfil the industrial demand that causes higher $\mathrm{CO}_{2}$ load to the treatment process, the $\mathrm{CO}_{2}$ removal efficiency is decreased. Therefore, the adjustment of operating parameters is considered to be the first and easiest method to improve the process and to prevent $\mathrm{CO}_{2}$ breakthrough in the treated gas. The existing process in the plant is continuous, which is not easy to be tested with new operating values during normal operation. This is because it will cause production specification problems, unit trips or high energy consumptions, which also affect both environment and operating costs. Therefore, the computer programs such as Aspen Plus and Aspen HYSYS have been developed for process simulation and studied for decades in order to explore the process development without interruption. This method has been used and shows good agreement with the real experimental result, which has been confirmed by many previous studies [2-8].

Several studies were conducted to investigate the effect of process parameters on acid gas removal efficiency and energy consumption in processes, especially at the reboiler of the stripper in the amine treating unit by both experimental methods [8-10] and process simulation methods using computer programs $[6,7,11]$. All of these studies performed sensitivity analysis by changing the operating parameters one by one from the base case individually. By doing so, the interaction effects were negligible. In order to investigate such effects systematically, the $2^{\mathrm{k}}$ factorial experimental design which is one of the powerful statistical methods can be applied to explore the significances of main and interaction effects on the considered response [12]. Then, the meaningful parameters are screened and used for process optimization.

In this study, the $\mathrm{CO}_{2}$ capture using MEA pilot plant from Notz et al.'s experiment [13] was modelled by Aspen Plus with equilibrium based methods to investigate the main and interaction effects of five parameters which were liquid-gas mass ratio $(L / G)$, sour gas temperature, lean MEA temperature, lean MEA concentration and $\mathrm{CO}_{2}$ concentration in sour gas on $\mathrm{CO}_{2}$ removal efficiency and reboiler specific heat duty. The $2^{\mathrm{k}}$ factorial experimental design was carried out to explore the significance of each main and interaction effect among them. As in this study, only low and high level values of parameters were used. Finally, the optimization of the $\mathrm{CO}_{2}$ removal efficiency and reboiler specific heat duty of the process will be reported as a guideline.

\section{Methodology}

\subsection{Process Description}

The basic conceptual flow diagram of the chemical absorption process for $\mathrm{CO}_{2}$ capture is illustrated in Fig. 1. Generally, $\mathrm{CO}_{2}$ containing waste gas was fed to the bottom of the absorber. The $\mathrm{CO}_{2}$ was chemically absorbed along the column by the lean MEA solvent, which was fed from the top of the absorber. While, the low $\mathrm{CO}_{2}$ concentration treated gas exited at the top of the absorber. The rich MEA solvent (leaving the bottom of the absorber) was heated by obtaining energy from the hot recycle lean solvent (leaving the bottom of the stripper) in order to reduce the reboiler heat duty. The heated rich MEA solvent was then fed to the stripper where $\mathrm{CO}_{2}$ was stripped. The external energy from either electricity or steam was provided at the reboiler for maintaining the process condition to regenerate solvent. As a result, the rich MEA solvent was regenerated and became the lean MEA solvent, which was recycled to the top of the absorber. At the top of the stripper, condenser was used to separate water and MEA entrainments from $\mathrm{CO}_{2}$ gas. The condensed water and MEA were then returned to the stripper as a reflux or drained as a condensate. Moreover, the lean MEA solution leaving the heat exchange was cooled down to provide suitable operating temperature for capturing $\mathrm{CO}_{2}$ in the absorber. Water or MEA make up stream may be included to maintain MEA concentration before reentering the absorber to compensate their loss $[9,13]$.

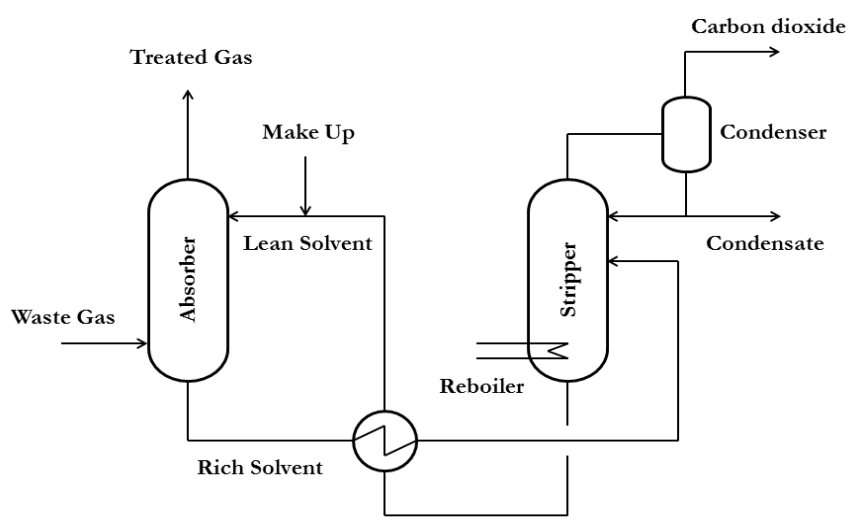

Fig. 1. The basic conceptual process flow diagram of carbon dioxide capturing with chemical absorption.

\subsection{Experiment Modeling}

The pilot plant experimental process parameters, which were obtained from Notz et al. [13], are summarized in Table 1 . They were modeled with an equilibrium model and an ENRTL-RK thermodynamics 
property method in Aspen Plus as illustrated in Fig. 2. Since the main consideration of the present work is to analyze the effect of process parameters on $\mathrm{CO}_{2}$ removal efficiency and specific heat duty at the reboiler, the equilibrium model was found to be sufficient to predict these two results. Additionally, the simulation with equilibrium model showed less complexity than that with rate-based model. It can be clearly found in the literature that the results of both equilibrium and rate-based models for the reactive distillation [14] and $\mathrm{CO}_{2}$ absorption [3, 15, 16] were quite similar, had small deviation from the experimental results and were sufficient for parametric analysis. In this study, the washer section was split from the absorber, as suggested by Li et al. [17], in order to simplify the model and help the absorber simulation to be much easier to converge.

\subsection{Chemical Reaction}

Absorption-desorption chemical reactions that used as governed reactions in $\mathrm{CO}_{2}$ capture process simulation were referred from a study of Arachchige et al. [2] and are presented as Eqs. (1)-(5). In an Aspen Plus, these chemical reaction equations were automatically given when the main components of the process were added. Also, the equilibrium constants (K) of Eqs. (1)-(5) used in Aspen Plus can be expressed in Eq. (6) as a function of temperature in Kelvin. According to built-in values provided by the programs, all constant parameters (a, b, c, and d) in Eq. (6) are given in Table 2.

Hydrolysis reaction

$$
\mathrm{ME} \mathrm{ACOO}^{-}+\mathrm{H}_{2} \mathrm{O} \leftrightarrow \mathrm{ME} \mathrm{A}+\mathrm{HCO}_{3}^{-}
$$

Dissociation of dissolved $\mathrm{CO}_{2}$

$$
\mathrm{CO}_{2}+2 \mathrm{H}_{2} \mathrm{O} \leftrightarrow \mathrm{HCO}_{3}^{-}+\mathrm{H}_{3} \mathrm{O}^{+}
$$

Dissociation of bicarbonate

$$
\mathrm{HCO}_{3}^{-}+\mathrm{H}_{2} \mathrm{O} \leftrightarrow \mathrm{H}_{3} \mathrm{O}^{+}+\mathrm{CO}_{3}^{2-}
$$

Dissociation of protonated MEA

$$
M E A^{+}+H_{2} \mathrm{O} \leftrightarrow M E A+H_{3} O^{+}
$$

Ionization of water

$$
2 \mathrm{H}_{2} \mathrm{O} \leftrightarrow \mathrm{OH}^{-}+\mathrm{H}_{3} \mathrm{O}^{+}
$$

Equilibrium constant

$$
\ln K=a+\frac{b}{T}+c \ln T+d T
$$

Table 1. The process and simulation parameters [13].

\begin{tabular}{lcc}
\hline Equipment & Absorber & Stripper \\
\hline Pressure (mbar) & 1000 & 2000 \\
Stage number & $5+1$ washer & $3+1$ washer \\
\hline Feed & Sour gas & Lean MEA \\
\hline Flow rate $(\mathrm{kg} / \mathrm{h})$ & 72 & 200.1 \\
Temperature $(\circ \mathrm{C})$ & 48.01 & 40.03 \\
Pressure (mbar) & 1004.49 & 2000 \\
Mass fraction & & \\
$\mathrm{CO}_{2}$ & 0.085 & 0.052 \\
$\mathrm{H}_{2} \mathrm{O}$ & 0.071 & 0.673 \\
$\mathrm{~N}_{2}$ & 0.743 & - \\
$\mathrm{O}_{2}$ & 0.101 & - \\
$\mathrm{MEA}_{\text {mol CO}} /$ mol MEA & - & 0.275 \\
\hline
\end{tabular}

\subsection{Responses Characterization}

Regarding the experimental results presented by Notz et al. [13], the simulation responses obtained in this study were reported in terms of $\mathrm{CO}_{2}$ removal efficiency (percentage) and reboiler specific heat duty (GJ/Ton $\mathrm{CO}_{2}$ ). The expressions of the two responses are given in Eqs. (7)-(9).

Mass of absorbed $\mathrm{CO}_{2}$ :

$$
\begin{aligned}
& \text { Mass of absorbed } \mathrm{CO}_{2}= \\
& \text { Mass of } \mathrm{CO}_{2} \text { in sour gas - Mass of } \mathrm{CO}_{2} \text { in treated gas }
\end{aligned}
$$

$\mathrm{CO}_{2}$ removal efficiency:

$$
\mathrm{CO}_{2} \text { removal efficiency }=\frac{\text { Mass of absorbed } \mathrm{CO}_{2}}{\text { Mass of } \mathrm{CO}_{2} \text { in sour gas }} \times 100
$$

Reboiler specific heat duty:

$$
\text { Reboiler specific heat duty }=\frac{\text { Reboiler heat duty }}{\text { Mass of absorbed } \mathrm{CO}_{2}}
$$

\subsection{The $2^{\mathrm{k}}$ Factorial Experimental Design}

In this study, the parametric analysis was performed with the $2^{\mathrm{k}}$ factorial experimental design, which is a wellknown method to statistically study the main and the interaction effects of parameters on the response by considering high and low levels of parameter. The ranges of these studied parameters (which are liquid-gas mass ratio $(\mathrm{L} / \mathrm{G})$, sour gas temperature, lean MEA temperature, lean MEA concentration and $\mathrm{CO}_{2}$ concentration in sour gas) were obtained from the literature of both experimental and simulation works [411, 18, 19], as summarized in Table 3. It should be mentioned that the $\mathrm{CO}_{2}$ loading on lean MEA solution for all cases were fixed at $0.265 \mathrm{~mol} \mathrm{CO}_{2} / \mathrm{mol} \mathrm{MEA}$ similar to the base case because it was not a studied 
parameter. In order to prevent an accumulation of $\mathrm{CO}_{2}$ in the recirculating lean MEA solution, the amount of desorbed $\mathrm{CO}_{2}$ from stripper was then adjusted to be that of absorbed $\mathrm{CO}_{2}$ in the absorber for each case. According to the $2^{\mathrm{k}}$ factorial experimental design of 5 parameters, 32 simulation cases were generated and analyzed.

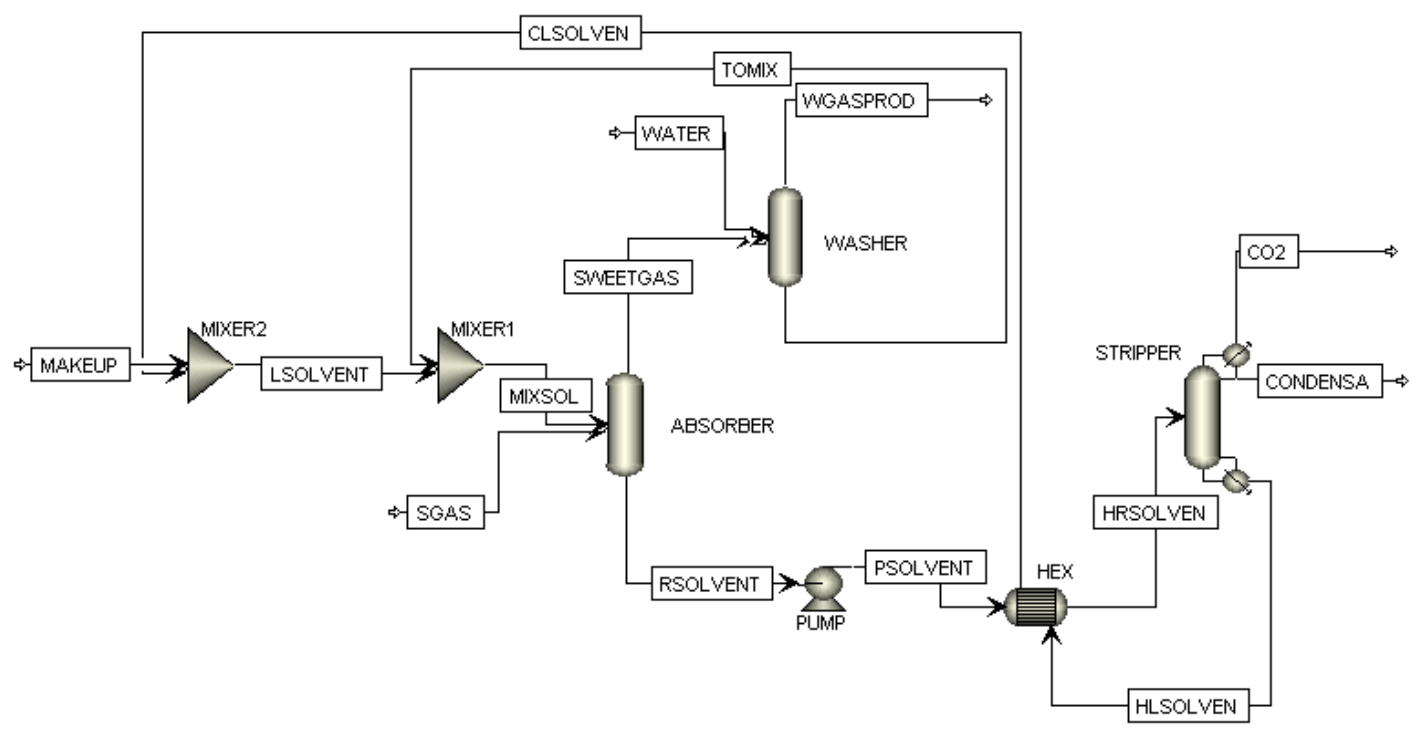

Fig. 2. The process flow diagram from Aspen Plus used in model validation and simulation.

Table 2. Equilibrium constants data to be used for calculation in Eq. (6).

\begin{tabular}{lccccc}
\hline Parameter & Eq. (1) & Eq. (2) & Eq. (3) & Eq. (4) & Eq. (5) \\
\hline$a$ & -0.52135 & 231.465 & 216.05 & -3.03833 & 132.899 \\
$b$ & -2545.53 & -12092.1 & -12431.7 & -7008.36 & -13445.9 \\
$c$ & 0 & -36.7816 & -35.4819 & 0 & -22.4773 \\
$d$ & 0 & 0 & 0 & -0.003135 & 0 \\
\hline
\end{tabular}

Table 3. Low and high values for each studied parameter in $2^{\mathrm{k}}$ factorial experimental design.

\begin{tabular}{lcc}
\hline Parameters & $\begin{array}{c}\text { Low } \\
(-)\end{array}$ & $\begin{array}{c}\text { High } \\
(+)\end{array}$ \\
\hline Liquid-gas mass ratio (L/G) & 0.5 & 12 \\
Sour gas temperature $\left({ }^{\circ} \mathrm{C}\right)$ & 45 & 60 \\
Lean MEA temperature $\left({ }^{\circ} \mathrm{C}\right)$ & 30 & 65 \\
Lean MEA concentration (wt.\%) & 10 & 50 \\
$\mathrm{CO}_{2}$ concentration in sour gas (wt. $\left.\%\right)$ & 4 & 68 \\
\hline
\end{tabular}

\section{Results and Discussion}

\subsection{Model Validation}

In order to conform an accuracy and a reliability of the simulation model used in the present work, the obtained responses of $\mathrm{CO}_{2}$ removal efficiency and reboiler specific heat duty were compared with those reported in the literature $[3,13,17]$. It was found that the simulation results obtained from this study were in good agreement with the experimental results reported by Notz et al. [13] results with average deviations of $3.38 \%$ and $4.61 \%$, respectively. Additionally, by comparing the obtained simulation results with that of literature $[3,17]$, the average deviations were found to be in an acceptable range as presented in Table 4.

\subsection{Effect of Main and Interaction Parameters}

From 32 cases of program simulation, the responses (which are $\mathrm{CO}_{2}$ removal efficiency and reboiler specific heat duty) were obtained and reported in Table 5. The data were further processed using analysis of variance (ANOVA) to determine contributions of the main parameters and the interactions between parameters on the two responses. In this work, the notation of each parameter was applied: A for liquid-gas mass ratio $(\mathrm{L} / \mathrm{G})$, B for sour gas temperature, $\mathrm{C}$ for lean MEA temperature, $D$ for lean MEA concentration and $\mathrm{E}$ for $\mathrm{CO}_{2}$ concentration in sour gas. From the simulation results, eight most significant interactions on $\mathrm{CO}_{2}$ removal efficiency and reboiler specific heat duty (occupying 99.84 and 97.39 contribution percentages, respectively) were further evaluated in terms of sum of squares (SS), contribution percentage, F-value, and P-value, as summarized in Tables 6 and 7. P-value is one of the indicators that represents the significance of the parameter in that for individual parameter or interaction with P-value less than 0.05 , the parameter or the interaction contributes statistically significant effect of the response [12]. On the other hand, if the P-value is higher than 0.05 , that parameter or interaction is considered to have statistically insignificant or no effect on the response. As shown in Tables 6 and 7, all the 
P-values are much lower than 0.05 . Therefore, it can be implied that liquid-gas mass ratio $(L / G)$, lean MEA temperature, lean MEA concentration and $\mathrm{CO}_{2}$ concentration in sour gas had statistically significant effects on both responses.

From Table 6, by evaluating the contribution percentage calculated from sum of squares (SS), the significance of main and interaction effects on the $\mathrm{CO}_{2}$ removal efficiency can be ordered as: $\mathrm{A}>\mathrm{E}>\mathrm{C}>$ $\mathrm{ADE}>\mathrm{AE}>\mathrm{AC}>\mathrm{D}>\mathrm{DE}$. Parameter A had a drastic influence of $75.82 \%$ contribution on the response, while parameter $\mathrm{E}$ showed the second most significance at $14.84 \%$ contribution. The remaining parameter C, interaction $\mathrm{ADE}$, interaction $\mathrm{AE}$, interaction $\mathrm{AC}$ and parameter D gave $1.87 \%, 1.80 \%, 1.70 \%, 1.59 \%$ and $1.51 \%$ contributions, respectively. Lastly, interaction DE contributed less than $1 \%$ on the effect of $\mathrm{CO}_{2}$ removal efficiency.

Likewise, the contribution percentages of main and interaction effects on the reboiler specific heat duty are summarized in Table 7. The significant order can be ranked as: $\mathrm{E}>\mathrm{A}>\mathrm{AE}>\mathrm{ACE}>\mathrm{CE}>\mathrm{C}>\mathrm{AC}>\mathrm{D}$. In this case, parameter $\mathrm{E}$ was the most significant parameter with $29.14 \%$ of contribution, followed by parameter A and interaction $\mathrm{AE}$ with $17.36 \%$ and $15.77 \%$ contribution, respectively. The fourth to seventh positions, which were interaction ACE, CE, the parameter $\mathrm{C}$ and interaction $\mathrm{AC}$, showed similar degrees of contribution at $8.38 \%, 8.28 \%, 7.36 \%$ and $7.27 \%$, respectively. Lastly, parameter D presented the lowest contribution of $3.83 \%$.

Table 4. Results comparison for the simulation and other studies for the experimental base case.

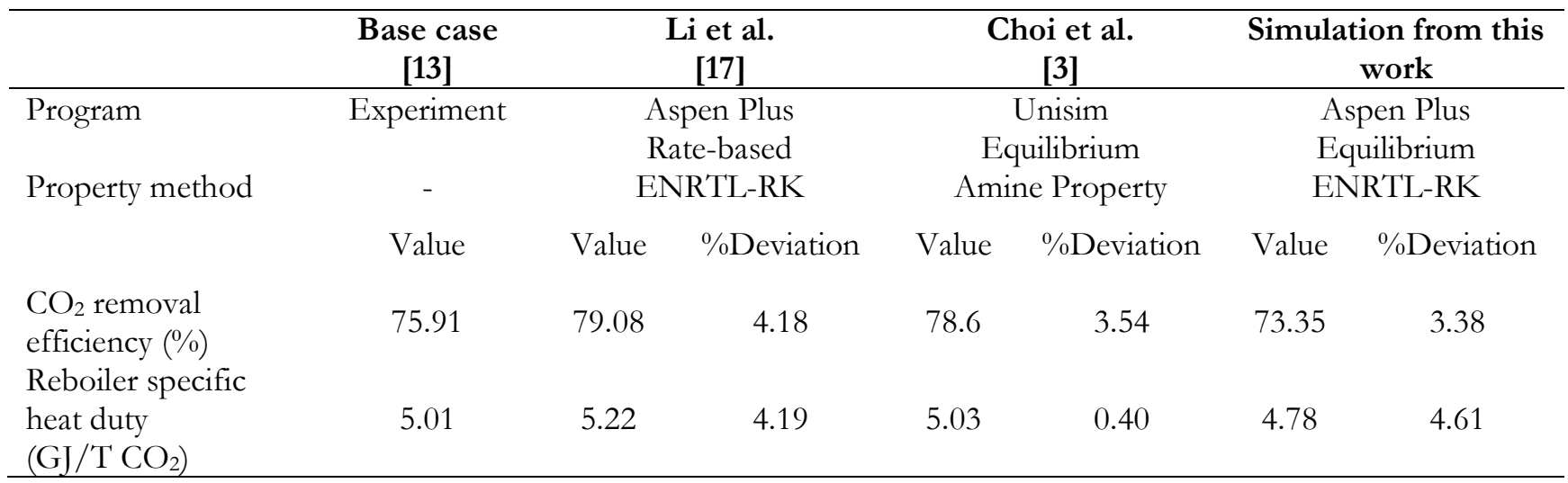

\subsection{Main Effect Plots}

In order to determine the effect of each parameter on the responses, the main effects plot, which shows an average value of response at low (-) and high $(+)$ levels (presented in Table 5), was generated as shown in Fig. 3). This plot shows positive and negative parametric effects, as well as significance of each parameter by its slope.

\subsubsection{Liquid-gas mass ratio $(\mathrm{L} / \mathrm{G})$}

Figure 3(A) shows a good agreement with the ANOVA table (Table 6) in that the liquid-gas mass ratio $(\mathrm{L} / \mathrm{G})$ had the most significant effect on the $\mathrm{CO}_{2}$ removal efficiency. It was found that $\mathrm{CO}_{2}$ removal efficiency increased as liquid-gas mass ratio $(\mathrm{L} / \mathrm{G})$ increased. This is because at high liquid-gas mass ratio (L/G), a larger amount of lean MEA solution was fed to the absorber so interfacial area between gas and liquid becomes larger [9]. However, at too of high liquid-gas mass ratio $(\mathrm{L} / \mathrm{G})$, large energy requirements at reboiler were observed, especially at low concentration of $\mathrm{CO}_{2}$ in feed gas, as shown in Fig. 3(B).

\subsubsection{Sour gas temperature}

Sour gas temperature showed the least significant effect on the responses among the studied parameters. Since $\mathrm{CO}_{2}$ absorption reaction in MEA solution is exothermic reaction [8], the $\mathrm{CO}_{2}$ removal efficiency and the specific heat duty at the boiler were found to be slightly decreased when sour gas temperature increased (within a temperature range of this study) as presented in Fig. 3(A) and 3(B).

\subsubsection{Lean MEA temperature}

By increasing lean MEA temperature, the $\mathrm{CO}_{2}$ removal efficiency was found to decrease accordingly as given in Fig. 3(A). This due to the fact that the solubility of $\mathrm{CO}_{2}$ in amine solution decreases as the temperature increases [8]. Additionally, it was found that at low lean MEA temperature, the reboiler energy requirement was considerable high. The results of these two responses confirmed that too low lean MEA temperature was not preferable. 
Table 5. Matrix design and responses of the $2^{\mathrm{k}}$ factorial experimental design.

\begin{tabular}{|c|c|c|c|c|c|c|c|}
\hline \multirow[t]{3}{*}{ Run } & \multicolumn{5}{|c|}{ Variables } & \multicolumn{2}{|c|}{ Responses } \\
\hline & $\begin{array}{l}\text { Liquid- } \\
\text { gas mass } \\
\text { ratio } \\
(\mathrm{L} / \mathrm{G})\end{array}$ & $\begin{array}{c}\text { Sour gas } \\
\text { temperature } \\
\left({ }^{\circ} \mathrm{C}\right)\end{array}$ & $\begin{array}{c}\text { Lean MEA } \\
\text { temperature } \\
\left({ }^{\circ} \mathrm{C}\right)\end{array}$ & $\begin{array}{c}\text { Lean MEA } \\
\text { concentration } \\
(w t . \%)\end{array}$ & $\begin{array}{c}\mathrm{CO}_{2} \\
\text { concentration } \\
\text { in sour gas } \\
(\text { wt. } \%)\end{array}$ & $\begin{array}{c}\mathrm{CO}_{2} \\
\text { removal } \\
\text { efficiency } \\
(\%)\end{array}$ & $\begin{array}{l}\text { Reboiler } \\
\text { specific } \\
\text { heat duty } \\
(\mathrm{GJ} / \text { Ton } \\
\left.\mathrm{CO}_{2}\right)\end{array}$ \\
\hline & $\mathrm{A}$ & $\mathrm{B}$ & $\mathrm{C}$ & $\mathrm{D}$ & $\mathrm{E}$ & R1 & R2 \\
\hline 1 & 0.5 & 45 & 30 & 10 & 4 & 15.79 & 7.87 \\
\hline 2 & 12 & 45 & 30 & 10 & 4 & 99.40 & 34.45 \\
\hline 3 & 0.5 & 60 & 30 & 10 & 4 & 16.55 & 8.12 \\
\hline 4 & 12 & 60 & 30 & 10 & 4 & 99.40 & 33.13 \\
\hline 5 & 0.5 & 45 & 65 & 10 & 4 & 15.45 & 8.35 \\
\hline 6 & 12 & 45 & 65 & 10 & 4 & 84.60 & 13.92 \\
\hline 7 & 0.5 & 60 & 65 & 10 & 4 & 14.06 & 8.07 \\
\hline 8 & 12 & 60 & 65 & 10 & 4 & 84.56 & 11.30 \\
\hline 9 & 0.5 & 45 & 30 & 50 & 4 & 28.23 & 4.33 \\
\hline 10 & 12 & 45 & 30 & 50 & 4 & 98.89 & 28.87 \\
\hline 11 & 0.5 & 60 & 30 & 50 & 4 & 24.20 & 4.17 \\
\hline 12 & 12 & 60 & 30 & 50 & 4 & 98.89 & 22.44 \\
\hline 13 & 0.5 & 45 & 65 & 50 & 4 & 26.91 & 4.20 \\
\hline 14 & 12 & 45 & 65 & 50 & 4 & 78.89 & 7.97 \\
\hline 15 & 0.5 & 60 & 65 & 50 & 4 & 22.66 & 4.09 \\
\hline 16 & 12 & 60 & 65 & 50 & 4 & 78.85 & 8.90 \\
\hline 17 & 0.5 & 45 & 30 & 10 & 68 & 2.07 & 4.83 \\
\hline 18 & 12 & 45 & 30 & 10 & 68 & 49.86 & 4.75 \\
\hline 19 & 0.5 & 60 & 30 & 10 & 68 & 1.80 & 4.41 \\
\hline 20 & 12 & 60 & 30 & 10 & 68 & 49.09 & 4.46 \\
\hline 21 & 0.5 & 45 & 65 & 10 & 68 & 2.02 & 4.94 \\
\hline 22 & 12 & 45 & 65 & 10 & 68 & 33.83 & 4.91 \\
\hline 23 & 0.5 & 60 & 65 & 10 & 68 & 1.76 & 4.35 \\
\hline 24 & 12 & 60 & 65 & 10 & 68 & 33.06 & 5.06 \\
\hline 25 & 0.5 & 45 & 30 & 50 & 68 & 3.79 & 2.71 \\
\hline 26 & 12 & 45 & 30 & 50 & 68 & 79.52 & 2.80 \\
\hline 27 & 0.5 & 60 & 30 & 50 & 68 & 3.25 & 2.84 \\
\hline 28 & 12 & 60 & 30 & 50 & 68 & 77.85 & 2.89 \\
\hline 29 & 0.5 & 45 & 65 & 50 & 68 & 3.70 & 2.65 \\
\hline 30 & 12 & 45 & 65 & 50 & 68 & 56.76 & 3.40 \\
\hline 31 & 0.5 & 60 & 65 & 50 & 68 & 3.14 & 2.86 \\
\hline 32 & 12 & 60 & 65 & 50 & 68 & 55.28 & 4.02 \\
\hline
\end{tabular}

Table 6. Effect of parameters on $\mathrm{CO}_{2}$ removal efficiency.

\begin{tabular}{lcccc}
\hline Interaction & $\begin{array}{c}\text { Sum of squares } \\
\text { (SS) }\end{array}$ & $\begin{array}{c}\text { Contribution } \\
\text { Percentage }\end{array}$ & F-value & P-value \\
\hline Overall Model & 38925.28 & 99.84 & 1515.87 & $8.68 \times 10^{-27}$ \\
A-A & 29608.46 & 75.82 & 10360.74 & $8.13 \times 10^{-29}$ \\
E-E & 5793.54 & 14.84 & 2027.3 & $9.44 \times 10^{-21}$ \\
C-C & 731.91 & 1.87 & 256.11 & $4.48 \times 10^{-11}$ \\
ADE & 702.31 & 1.80 & 245.76 & $6.73 \times 10^{-11}$ \\
AE & 665.38 & 1.70 & 232.83 & $1.14 \times 10^{-10}$ \\
AC & 622.28 & 1.59 & 217.75 & $2.19 \times 10^{-10}$ \\
D-D & 590.82 & 1.51 & 206.74 & $3.60 \times 10^{-10}$ \\
DE & 210.58 & 0.54 & 73.69 & $2.45 \times 10^{-6}$ \\
Residual & 125.2 & 0.32 & & \\
Total & 39050.8 & & & \\
\hline
\end{tabular}


Table 7. Effect of parameters on reboiler specific heat duty.

\begin{tabular}{lcccc}
\hline Interaction & $\begin{array}{c}\text { Sum of squares } \\
(\text { SS) }\end{array}$ & $\begin{array}{c}\text { Contribution } \\
\text { Percentage }\end{array}$ & F-value & P-value \\
\hline Overall Model & 2297.20 & 97.39 & 107.43 & $2.31 \times 10^{-16}$ \\
E-E & 687.27 & 29.14 & 257.13 & $5.61 \times 10^{-14}$ \\
A-A & 409.37 & 17.36 & 153.16 & $1.19 \times 10^{-11}$ \\
AE & 371.88 & 15.77 & 139.13 & $3.11 \times 10^{-11}$ \\
ACE & 197.68 & 8.38 & 73.96 & $1.21 \times 10^{-8}$ \\
CE & 195.41 & 8.28 & 73.11 & $1.34 \times 10^{-8}$ \\
AC & 173.69 & 7.36 & 64.98 & $3.76 \times 10^{-8}$ \\
C-C & 171.54 & 7.27 & 64.18 & $4.19 \times 10^{-8}$ \\
D-D & 90.36 & 3.83 & 33.8 & $6.34 \times 10^{-6}$ \\
Residual & 61.48 & 2.61 & & \\
Total & 2358.67 & & & \\
\hline
\end{tabular}
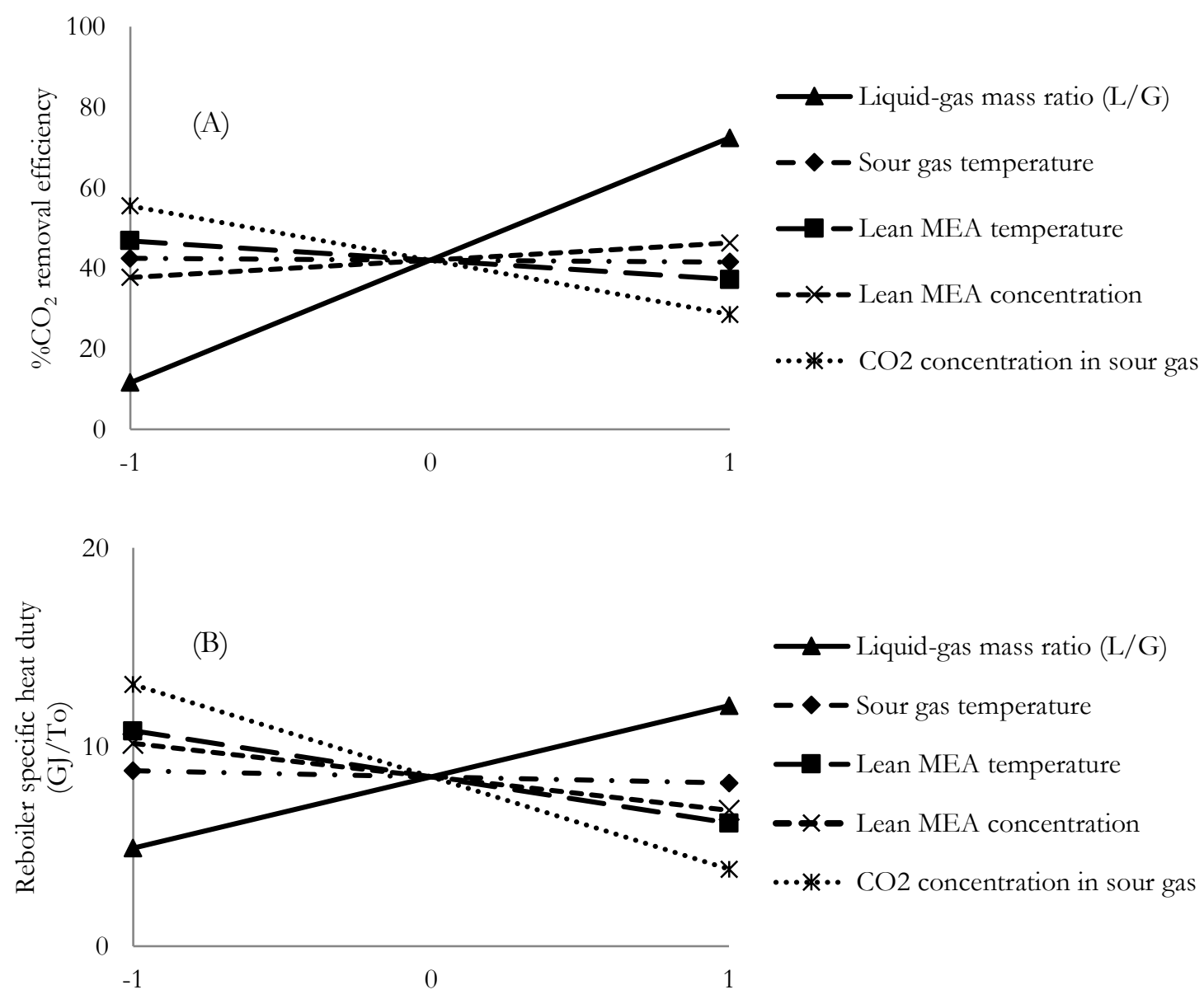

Fig. 3. Main effect plot of parameters on responses: (A) $\mathrm{CO}_{2}$ removal efficiency and (B) the reboiler specific heat duty.

\subsubsection{Lean MEA concentration}

Figures 3(A) and 3(B) show that lean MEA concentration positively affect both $\mathrm{CO}_{2}$ removal efficiency and reboiler specific heat duty in that the high lean MEA concentration results in the high $\mathrm{CO}_{2}$ removal efficiency and the low reboiler specific heat duty. It can be reasoned that at higher lean MEA concentration, there are more free MEA to react with $\mathrm{CO}_{2}$ [11]; thus, the $\mathrm{CO}_{2}$ removal efficiency was found to increase. On the reboiler side, the high lean MEA concentration resulted in the low $\mathrm{CO}_{2}$ loading on rich MEA solution. Therefore, low reboiler specific heat duty was then observed [9].

In the existing amine based $\mathrm{CO}_{2}$ capture process, the lean MEA concentration is one of the most convenient parameters to be manipulated in order to improve the overall process performance of both $\mathrm{CO}_{2}$ removal efficiency and reboiler specific heat duty. However, severe equipment corrosion may be faced if too high of a concentration of MEA was used [20]. 


\subsection{5. $\mathrm{CO}_{2}$ concentration in sour gas}

$\mathrm{CO}_{2}$ concentration in sour gas is normally not a manipulated variable. In the real process, the $\mathrm{CO}_{2}$ concentration is varied by the condition of combustion or the production rate. However, by increasing $\mathrm{CO}_{2}$ concentration in sour gas, the $\mathrm{CO}_{2}$ removal efficiency was found to decrease (Fig. 3(A)) and the reboiler specific heat duty was also decreased (Fig. 3(B)). Even though the low $\mathrm{CO}_{2}$ loading on rich MEA solution can be achieved at low $\mathrm{CO}_{2}$ concentration in sour gas, the low specific heat duty of solvent regeneration cannot be observed. This is because the surplus MEA solution entering the stripper still needed to be heated. Thus, the reboiler duty was then found to increase as $\mathrm{CO}_{2}$ concentration in sour gas decreased. In order to prevent this unfavorable behavior, the flow rate of lean MEA solution is suggested to be well matched with the concentration of $\mathrm{CO}_{2}$ in sour gas.

\subsection{Optimization}

From the ANOVA analysis in Tables 6 and 7 and the main effect plot in Fig. 3, it was found that the liquidgas mass ratio $(\mathrm{L} / \mathrm{G})$ is the most significant parameter that promotes $\mathrm{CO}_{2}$ removal efficiency and significantly decreases reboiler specific duty. Therefore, this parameter was then selected to be the key factor in process optimization. The remaining parameters (i.e., lean MEA temperature and lean MEA concentration) were considered as supportive parameters in process optimization for improving $\mathrm{CO}_{2}$ removal efficiency and reducing reboiler specific duty of the MEA based $\mathrm{CO}_{2}$ capture process. From Table 5, cases 10 and 12, which operated at high level of liquid-gas mass ratio (L/G), low lean MEA temperature and high lean MEA concentration, but low $\mathrm{CO}_{2}$ concentration in sour gas, showed the same very high $\mathrm{CO}_{2}$ removal efficiencies at $98.89 \%$. However, the reboiler specific heat duty values of both cases were found to be very high at 28.87 and 22.44 GJ/Ton $\mathrm{CO}_{2}$, respectively. These numbers are considerably high compared with $4.00 \mathrm{GJ} /$ Ton $\mathrm{CO}_{2}$ of the typical reboiler specific heat duty for the MEA based process [21]. Cases 26 and 28, which were run at high level of liquid-gas mass ratio (L/G), low lean MEA temperature, high lean MEA concentration and high $\mathrm{CO}_{2}$ concentration in sour gas, showed much lower $\mathrm{CO}_{2}$ removal efficiencies $(79.52 \%$ and $77.85 \%$, respectively) than cases 10 and 12 . The $\mathrm{CO}_{2}$ removal efficiencies of $77.85 \%$ and $79.52 \%$ were considered to be in an acceptable range within $75 \%$ - 95\% [22] but lower than the typical amine based $\mathrm{CO}_{2}$ capture process of $85-95 \%$ [23]. Interestingly, the results of reboiler specific heat duty of cases 26 and 28 (2.80 and 2.89 GJ/Ton $\mathrm{CO}_{2}$, respectively) were much lower than that of cases 10 and 12 and that of typical MEA based $\mathrm{CO}_{2}$ capture process. From these cases, it can be mentioned that $\mathrm{CO}_{2}$ concentration in sour gas also played an important role on the achievement of process optimization. As a preliminary guideline, the operating liquid-gas mass ratio $(\mathrm{L} / \mathrm{G})$ should be adjusted regarding the $\mathrm{CO}_{2}$ concentration in sour gas. At too high liquid-gas mass ratio $(\mathrm{L} / \mathrm{G})$, the large energy requirement (for heating surplus MEA solution at reboiler and circulating the excess liquid) will be experienced. On the other hand, at too low liquid-gas mass ratio $(\mathrm{L} / \mathrm{G})$, the $\mathrm{CO}_{2}$ removal efficiency will not meet the emission requirement.

\section{Conclusions}

This study performed a parametric analysis of $\mathrm{CO}_{2}$ captured process using aqueous MEA solution by the $2^{\mathrm{k}}$ factorial experimental design. Firstly, the $\mathrm{CO}_{2}$ capture process was successfully modeled in Aspen Plus with an ENRTL-RK property package and equilibrium based method as well as validated with experimental and simulated results obtained from the literature. The five operating parameters (including liquid-gas mass ratio $(\mathrm{L} / \mathrm{G})$, sour gas temperature, lean MEA temperature, lean MEA concentration and $\mathrm{CO}_{2}$ concentration in sour gas) were investigated for their main and interaction effects on the $\mathrm{CO}_{2}$ removal efficiency and the reboiler specific heat duty using the $2^{\mathrm{k}}$ factorial experimental design.

From analysis of variance or ANOVA, the results showed that main and interaction effects affected the $\mathrm{CO}_{2}$ removal efficiency with $99.84 \%$ contribution. Among these effects, liquid-gas mass ratio or $\mathrm{L} / \mathrm{G}$ was the most significant effect with $75.82 \%$ contribution. For the reboiler specific heat duty, main and interaction effects affected the reboiler specific heat duty with $97.39 \%$ contribution. Among these effects, the $\mathrm{CO}_{2}$ concentration in sour gas showed the highest 29.14\% contribution. Additionally, the sour gas temperature was found to have the least contribution on both $\mathrm{CO}_{2}$ removal efficiency and reboiler specific heat duty as observed from main effect plots of parameters on responses.

It is suggested that the liquid-gas mass ratio $(\mathrm{L} / \mathrm{G})$ should be adjusted to be well matched with $\mathrm{CO}_{2}$ concentration in sour gas in order to achieve a desired $\mathrm{CO}_{2}$ removal efficiency with low specific reboiler heat duty. Also, the lean MEA concentration should be increased to promote $\mathrm{CO}_{2}$ removal efficiency and reduce specific reboiler heat duty. To avoid severe equipment corrosion by highly concentrated MEA solution, the maximum operable lean MEA concentration is suggested to be further investigated in an aspect of material corrosion. Lastly, the supportive parameters (temperature of lean MEA and sour gas) should be tuned after adjusting the liquid-gas mass ratio $(\mathrm{L} / \mathrm{G})$ in order to meet the required $\mathrm{CO}_{2}$ removal efficiency and reboiler specific heat duty.

\section{Acknowledgement}

The first author would like to express appreciation to Covestro (Thailand) Co., Ltd. for supporting the Master's degree scholarship, and the Department of Chemical 
Technology, Faculty of Science, Chulalongkorn University for providing research facilities. The last author thanks Chulalongkorn University for providing the Ratchadapisek Sompoch Endowment Fund (2019), Chulalongkorn University (CU-GR_62-023_23_011) and the National Research Council of Thailand for providing the MidCareer Research Grant (NRCT5-RSA63001-24).

\section{References}

[1] M. Garcia, H. K. Knuutila, and S. Gu, "ASPEN PLUS simulation model for $\mathrm{CO}_{2}$ removal with MEA: Validation of desorption model with experimental data," Journal of Environmental Chemical Engineering, vol. 5, pp. 4693-4701, 2017.

[2] U. S. P. R. Arachchige and M. C. Melaaen, "Aspen plus simulation of $\mathrm{CO}_{2}$ removal from coal and gas power plant," Energy Procedia, vol. 23, pp. 391-399, 2012.

[3] J. Choi, H. Cho, S. Yun, M. Jang, S. Oh, M. Binns, and J. Kim, "Process design and optimization of MEA-based $\mathrm{CO}_{2}$ capture processes for non-power industries," Energy, vol. 185, pp. 971-980, 2019.

[4] R. Dutta, L. O. Nord, and O. Bolland, "Prospects of using equilibrium-based column models in dyanamics process simulation of post-combustion $\mathrm{CO}_{2}$ capture for coal-fired power plant," Fuel, vol. 202, pp. 85-97, 2017.

[5] Y. Zhang and C. Chen, "Modelling $\mathrm{CO}_{2}$ absorption and desorption by aqueous monoethanolamine solution with Aspen rate-based model," Energy Procedia, vol. 37, pp. 1584-1596, 2013.

[6] S. Oh, M. Binns, H. Cho, and J. Kim, "Energy minimization of MEA-based $\mathrm{CO}_{2}$ capture process," Applied Energy, vol. 169, pp. 353-362, 2016.

[7] L. E. Øi, "Aspen HYSYS simulation of $\mathrm{CO}_{2}$ removal by amine absorption from a gas based power plant," in SIMS2007 Conference, Göteborg, Sweden, 2007, pp. 73-81.

[8] H. J. Qeshta, S.Abuyahya, P. Pal, and F. Banat, "Sweetening liquefied petroleum gas (LPG): Parametric sensitivity analysis using Aspen HYSYS," Journal of Natural Gas Science and Engineering, vol. 26, pp. 10111017, 2015.

[9] M. S. Jassim, "Sensitivity analyses and optimization of a gas sweetening plant for hydrogen sulfide and carbon dioxide capture using methyldiethanolamine solutions," Journal of Natural Gas Science and Engineering, vol. 36, pp. 175-183, 2016.

[10] F. Vega, M. Cano, L. M. Gallego, S. Camio, J. A. Camio, and B. Navarrete, "Evaluation of MEA 5M performance at different $\mathrm{CO}_{2}$ concentration of flue gas tested at a $\mathrm{CO}_{2}$ capture lab-scale plant," Energy Procedia, vol. 114, pp. 6222-6228, 2017.

[11] H. Ghanbarabadi and F. K. Z. Gohar, "Optimization of MDEA concentration in flow of input solvent to the absorption tower and its effect on the performance of other processing facilities of gas treatment unit in Sarakhs refinery," Journal of Natural Gas Science and Engineering, vol. 20, pp. 208-213, 2014.
[12] T. Yurata, P. Piumsomboon, and B. Chalermsinsuwan, "Effect of contact force modeling parameters on the system hydrodynamics of spouted bed using CFD-DEM simulation and $2 \mathrm{k}$ factorial experimental design," Chemical Engineering Research and Design, vol. 153, p. 401-418, 2020.

[13] R. Notz, H. P. Mangalapally, and H. Hasse, "Post combustion $\mathrm{CO}_{2}$ capture by reactive absorption: Pilot plant description and results of systematic studies with MEA," International Journal of Greenhouse Gas Control, vol. 6, pp. 84-112, 2012.

[14] J. Peng, S. Lextrait, T. F. Edgar, and R. B. Eldridge, "A comparison of steady state equilibrium and ratebased models for packed reactive distillation columns," Industrial \& Engineering Chemistry Research, vol. 41, pp. 2735-2744, 2002.

[15] Y. Wu, F. Wu, G. Hu, N. R. Mirza, G. W. Stevens, and K. A. Mumford, "Modelling of a post combustion carbon dioxide capture absorber using potassium carbonate solvent in Aspen Custom Modeller," Chinese Journal of Chemical Engineering, vol. 26, pp. 2327-2336, 2018.

[16] L. Duan, M. Zhao, and Y. Yang, "Integration and optimization study on the coal-fired power plant with $\mathrm{CO}_{2}$ capture using MEA," Energy, vol. 45, pp. 107-116, 2012.

[17] B. Li, N. Zhang, and R. Smith, "Simulation and analysis of $\mathrm{CO}_{2}$ capture process with aqueous monoethanolamine solution," Applied Energy, vol. 161, pp. 707-717, 2016.

[18] S. Sahraie, H. Rashidi, and P. Veleh-e-Sheyda, "An optimization framework to investigate the $\mathrm{CO}_{2}$ capture performance by MEA: Experimental and statistical studies using Box-Behnken design," Process Safety and Environmental Protection, vol. 122, pp. 161-168, 2019.

[19] S. Laribi, L. Dubois, G. De Weireld, and D. Thomas, "Study of the post-combustion $\mathrm{CO}_{2}$ capture process by absorption-regeneration using amine solvents applied to cement plant flue gases with high CO2 contents," International Journal of Greenhouse Gas Control, vol. 90, p. 102799, 2019.

[20] J. Kittle, R. Idem, D. Gelowitz, P. Tontiwachwuthikul, G. Parrain, and A. Bonneau, "Corrosion in MEA units for $\mathrm{CO}_{2}$ capture: Pilot plant studies," Energy Prcedia, vol. 1, pp. 791-797, 2009.

[21] L. E. Øi and S. H. P. Kvam, "Comparison of energy consumption for different $\mathrm{CO}_{2}$ absorption configurations using differenet simulation tools," Energy Procedia, vol. 63, pp. 1186-1195, 2014.

[22] The Integrated Environmental Control Model Team, "IECM Technical Documentation: Aminebased Post-Combustion $\mathrm{CO}_{2}$ Capture," Department of Engineering and Public Policy, Carnegie Mellon University, Pittsburgh, Pennsylvania, USA, 2019.

[23] B. Metz, O. Davidson, H. de Coninck, M. Loos, and L. Meyer, "Capture of $\mathrm{CO}_{2}$," in IPCC Special Report on Carbon Dioxide Capture and Storage. New York, USA, 2005, ch. 3, sec. 3.7.5.1, pp. 150. 


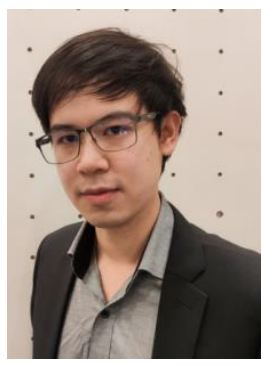

Thapanat Chuenphan recieved B.Sc. in Chemical Engineering from the Department of Chemical Technology, Chulalongkorn University, Bangkok, Thailand in 2014 with First Class Honor, and currently is a Master's student in Petrochemisty and Polymer Science at Chulalongkorn University. He has been being with Covestro (Thailand) Co., Ltd. since August 2014 as a process engineer in polycarbonate production plant. He has 6 years of experience in petrochemical process and operations, process improvement, process safety and turnaround management.

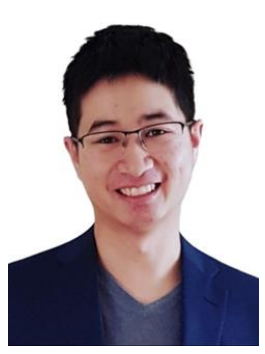

Tarabordin Yurata is currently a Ph.D. candidate at the Department of Chemical Technology, Faculty of Science, Chulalongkorn University, supported by Royal Golden Jubilee Ph.D. scholarship by The Thailand Research. He has a background in both computational fluid dynamics (CFD) and process simulation. His researches focus on chemical looping, discrete element method (DEM) simulation, bulk solid handling, and process intensification.

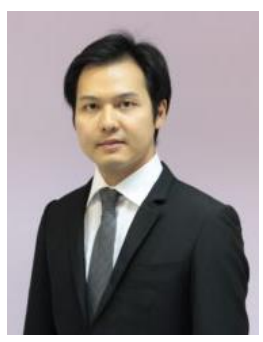

Teerawat Sema, Ph.D. received Ph.D. in Engineering from the University of Regina, Canada. He holds a Master of Science in Petrochemical Technology from, Chulalongkorn University and a Bachelor of Engineering in Petrochemical and Polymeric Materials from Silpakorn University. His research interest includes High Efficiency $\mathrm{CO}_{2}$ Separation and Purification with Reactive Solvents, Heat and Mass Transfer with Chemical Reactions, and Intelligent and Knowledge-based Systems.

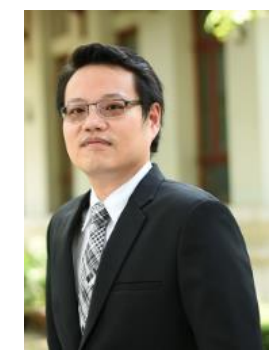

Benjapon Chalermsinsuwan, Ph.D. is an Associate Professor of Department of Chemical Technology at Faculty of Science, Chulalongkorn University. He holds a B.Sc. in Chemical Engineering from Chulalongkorn University and Ph.D. degree in Chemical Technology from Chulalongkorn University. His research interest relates to the several topics including: computational fluid dynamics (CFD) simulation, experimental design and analysis, multiphase flow/fluidization technology and carbon dioxide $\left(\mathrm{CO}_{2}\right)$ capture and utilization 